\title{
TMD clinical diagnostic classification (Temporo Mandibular Disorders)
}

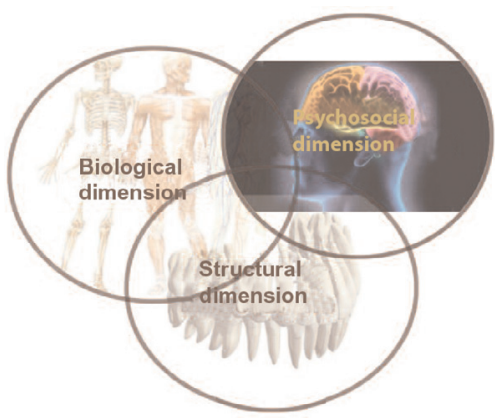

\author{
Olivier LAPLANCHE, Elodie EHRMANN, \\ Pierre PEDEUTOUR, Gerard DUMINIL
}

ABSTRACT

Practitioners should aim to diagnose as early as possible the development of malfunction of the masticatory system, or temporomandibular disorder (TMD), that causes pain, discomfort and a decrease in functional efficiency, especially in those patients whose occlusion is being rehabilitated in the course of orthodontic treatment. This is particularly true for the segment of the patient population who are characterized by certain risk factors.

Armed with a good understanding of the diagnostic classification of TMD, orthodontists will be better prepared to pinpoint and diagnose TMD and, if necessary, adopt the most appropriate mode of therapy for treating it.

Thanks to a good understanding of TMD nosology, orthodontists will be able to distinguish between muscular and joint disorders and then manage patients in accordance with specific diagnostic criteria.

\section{KEY WORDS}

\author{
Masticatory system, \\ Occlusion, \\ Malfunctioning of the masticatory system, \\ Muscles of mastication, \\ Temporomandibular joint - TMJ.
}




\section{1 - INTRODUCTION}

The objective of orthodontic treatment is to obtain optimal occlusion with good centric relation and with the mandible well guided and in a solid position at rest. The result should be the achievement of good masticatory function and excellent esthetic appearance of the face and the dentition, all of which contribute to the longevity of the masticatory system.

In this context, orthodontists are often called upon to swiftly recognize and manage any possible dysfunction of the masticatory system (known as temporomandibular disorder, or TMD). This recognition and management should begin at the initial consultation, where the clinician should be alert for any indications of potential TMD that may already be symptomatic or still unrecognizable clinically. Further opportunities are presented during the course of treatment and in post-treatment, where TMD could diminish the quality of results or be provoked by an inappropriate intervention by the orthodontist. Finally, a TMD problem may itself be the reason for the consultation because the patient or referring physician justly considered an orthodontist to be the appropriate specialist in treating problems of occlusion and malfunction of the masticatory system.

To discern and, if necessary, properly manage cases of dysfunctions of the masticatory system, orthodontists must have a good understanding of how they are defined, their etiology, the principal clinical signs that characterize them, the way they evolve, and the complications and risks that accompany them.
The essential definition of masticatory dysfunctions describes them as pathoses of the oral musculature and articulation that, according to the type of malfunction, can generate:

- pain,

- functional problems that range from mild discomfort to real functional handicaps,

- and/or structural changes, including alterations of the articular surfaces and muscular configurations.

Orthodontists called upon to deal with certain symptoms of clinical dysfunction will be faced with a variety of problems: How should a specific pathosis presented by the patient be addressed therapeutically? How should this treatment program be adjusted to react to new symptoms (e.g. by modifying, accelerating or interrupting therapy)? And what are the possible structural consequences of the malfunction within the anatomo-functional framework of the therapy. In reality, all occlusal rehabilitation must be accomplished in harmony with a physiological mandibular reference position, which in orthodontics is a stabilized articular relationship ${ }^{35}$. This, according to Philippe ${ }^{38}$, should generate a harmonious state of mutual tolerance between the different systems of the masticatory system.

The objective of this article is to help orthodontists deal with the malfunction problems they encounter in their daily practices by recalling some of the basic features of TMD and its etiology, before presenting a clinical diagnostic classification that will help them detect and diagnose indications of TMD. 


\section{2 - DEFINITION AND FUNDAMENTAL ASPECTS OF TMD}

TMD is defined as a muscular and articular disorder ${ }^{21}$. This term includes anatomical, histological, and functional anomalies in the functioning of the muscular and/or articular components of the system that are accompanied by highly varied clinical signs and symptoms. The general clinical consequences of discomfort, pain, and disturbances of mastication are similar in most patients, and can thus be subsumed in the non-specific term, 'TMD'.

Accordingly, TMD is characterized by clinical signs of pain or malfunction occurring jointly or separately ${ }^{11,34}$.

- pain in the temporomandibular joint (TMJ),

- articular sounds,

- pain in the muscles of mastication,

- anomalies in mandibular movements,

- signs and symptoms that may be associated with orofacial pain and/ or cervicoscapular problems.

A malfunction is an expression of disturbance of functional activities that can provoke patients to make adaptive changes. TMD corresponds, then, to pain and dysfunction in the masticatory system related to musculoskeletal anomalies and can refer to either or both of the affected systems (muscular and articular).

TMD problems are widespread, affecting $90 \%$ of the general population at one life stage or another ${ }^{42}$, especially 20-40 year-old women. However, only $10 \%$ of affected individuals seek treatment for pain, and, less frequently, for articular noises ${ }^{5}$.

\section{2 - 1 - Etiopathology of TMD}

Many authors ${ }^{15-37}$ have proposed an etiopathological, multi-dimensional model for TMD that integrates (Fig. 1):

- a biological dimension: the general, or systemic, influence the muscular and articular aspects of TMD;

- a psychosocial dimension: the psychological conformation of subjects in the context of their environmental and cultural milieu influencing masticatory behavior and their perception of malfunction and pain ${ }^{13}$;

- and a structural dimension: the local somatic component of the musculoskeletal organization associated with the TMJ and occlusion.

Currently, a consensus exists on the multi-factorial etiology of TMD that comprises structural, neuroendocrine, emotional, functional, and behavioral elements that can be classified clinically as 'pre-disposing', 'triggering' and 'maintenance' aspects of TMD (Fig. 2).

In this model, the role played by occlusion is controversial ${ }^{7-9,12,19,20,39,43}$. De Boever ${ }^{9}$ sums up the current status of occlusion, saying, "It is not primordial, but it is not a nullity."

It is widely acknowledged that orthodontic treatment can neither create a TMD problem nor cure one ${ }^{10,26,27}$.

Thus, dentists should not undertake major occlusal rehabilitation programs as a means of treating TMD but they should, nevertheless, accept the importance of optimizing occlusal function. 


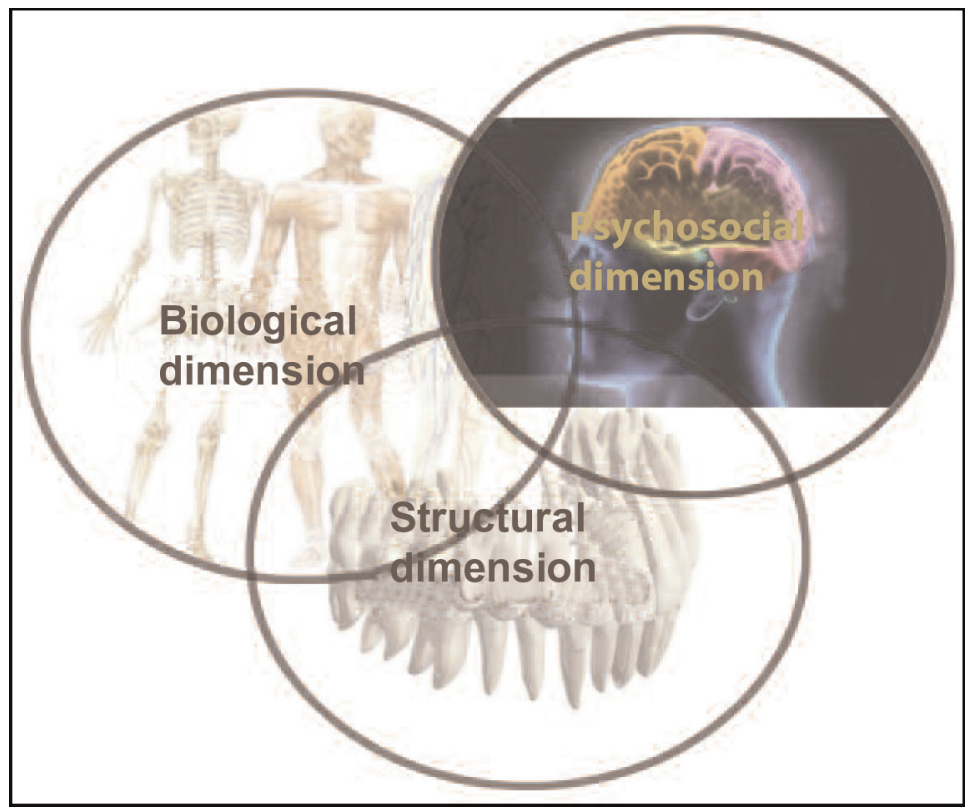

Figure 1

Etiopathological model of TMD in three dimensions.

Orthodontists can refer to "the advice of experts" and a biomechanical $\operatorname{logic}^{2,34,35}$ to systematically reduce the constraints operating on different components of the masticatory complex (articular, muscular, and dental), and to optimize occlusal function based on theoretical models ${ }^{28}$.

In addition to anomalies of form, tooth position, and arch arrangement, examiners must evaluate functional anomalies of occlusion and their potential effect on other systems ${ }^{23}$.

As a schematic conception, we can assume that, in general, TMD develops when there is some defect in mandibular posture, excessive constraint in both time and force, and a non-adaptive or disproportionate response from the masticatory structures and/or the central nervous system, resulting most often from strain exceeding the patient's adaptive capacity.

\section{2 - 2 - Global diagnostic approach}

Dentists should adopt a diagnostic approach for TMD based on the normalized and standardized clinical methods now available complemented by photographic and radiographic images ${ }^{4}$.

An essential first step is making an exclusion analysis, ruling out non-TMD pathoses whose prognoses could be far more serious, 32,33 .

A second imperative in TMD diagnosis is to adopt a global, bio-psychosocial viewpoint that, as suggested in 


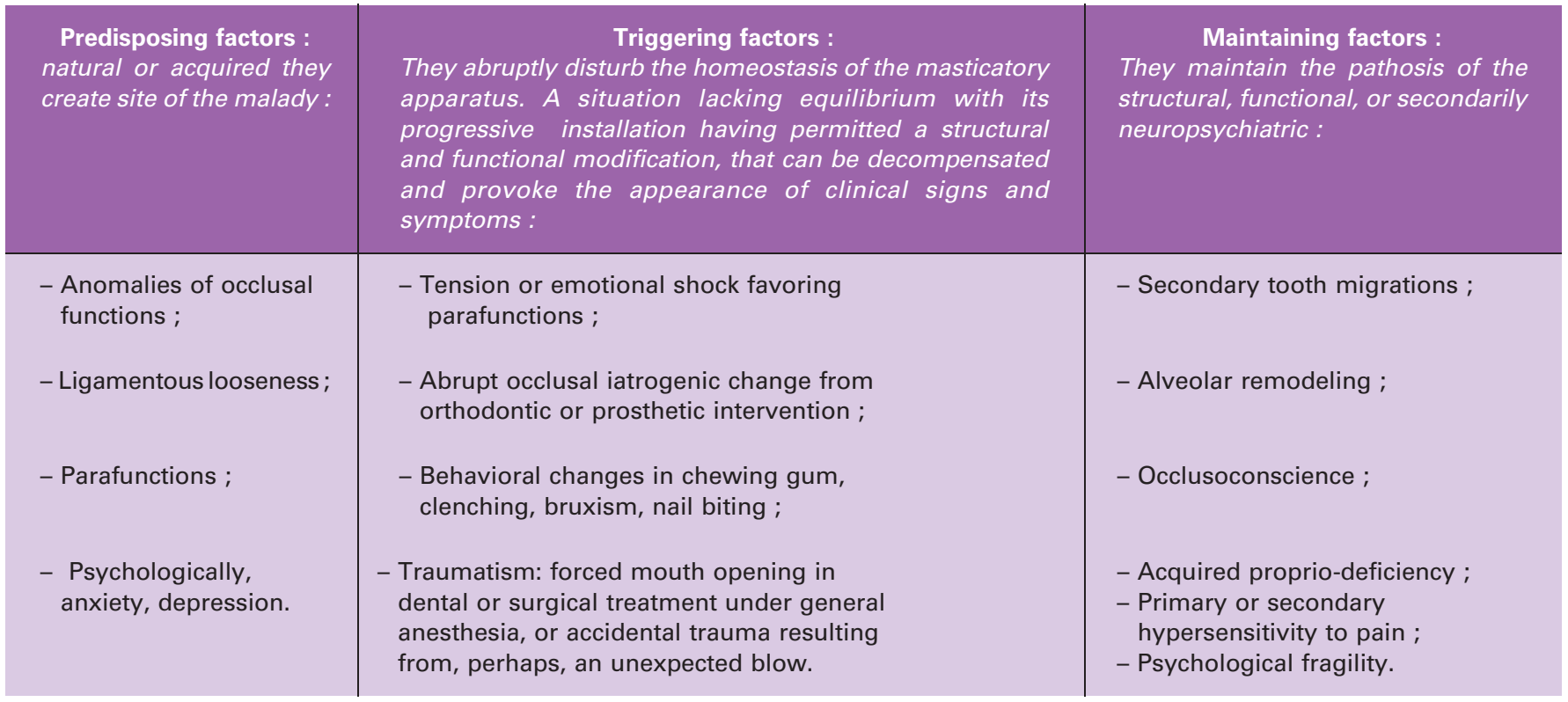

Figure 2

Etiological or risk factors for TMD: summary table.

the previous pages, goes well beyond a mechanistic dental assessment.

Because electronic devices have no proven reliability, orthodontists should use them guardedly in making therapeutic decisions. Careful and complete anamnesis, medical communication, and clinical examination are of primary importance in detecting and diagnosing $\mathrm{TMD}^{4}$. John et al. ${ }^{18}$ have shown the reliability of well conducted clinical examination.

\section{2 - 3 - Therapeutic approach}

None of the different therapeutic modalities for TMD has proven to be superior to all others, so dentists managing the problem must direct their efforts to relieving symptoms with conservative, reversible techniques that are as non-invasive as possible.

Some authors ${ }^{1,35}$ also insist that in the absence of scientific proofs, dentists must be guided by clinical and biological logic, i.e. they should reduce noxious constraints affecting various elements of the masticatory complex, the teeth, the TMJ, and the musculature, as the immutable objective of any major occlusal rehabilitation.

tered by orthodontists either clinically or in the intake interview in Table I: 


\begin{tabular}{|c|}
\hline Clinical signs and symptoms of TMD \\
\hline Anomalies of mandibular movement \\
\hline Articular noises \\
\hline Pain \\
\hline Accessory symptoms potentially associated with TMD \\
\hline
\end{tabular}

Table I

\section{3 - 1 - Anomalies of mandibular movement}

Table II shows measurements for various anomalies in mandibular movement, which include:

- limitation of movement of the mandible, which is frequently related to a TMJ problem, such as a disc displacement or muscular malfunction;

- lack of control of mandibular translation and rotary movement because of acquired or systemic ligamentous laxity ${ }^{14}$.

In some cases, these problems can be qualitative (Tab. III, Fig. 3) with alterations in mandibular trajectory on opening (e.g. deviations or deflections).

\section{3 - 2 - Articular sounds ${ }^{22}$}

\section{3- 2 - 1 - Clicking}

These sounds occur most frequently when the condyle moves over the posterior glenoid of the disc during the translational actions of opening, propulsion, and contralateral excursion: there is then a lack of condyle disc contact during maximum inter-

\begin{tabular}{|l|c|}
\hline \multicolumn{1}{|c|}{$\begin{array}{c}\text { Measurement of anomalies } \\
\text { of mandibular movement }\end{array}$} & $\begin{array}{c}\text { Mouth opening in } \\
\mathbf{m m}\end{array}$ \\
\hline Normal mouth opening & 35 to 45 \\
\hline Limitation of normal mouth opening & $<$ at 35 \\
\hline Exaggeration of mouth opening & $>50$ \\
\hline
\end{tabular}

Table /I

\begin{tabular}{|c|c|}
\hline $\begin{array}{c}\text { Qualitative alterations in } \\
\text { mandibular movement }\end{array}$ & Trajectory \\
\hline Mandibular deviation & Bayonet opening \\
\hline Mandibular deflection & Deviated rectangular opening \\
\hline
\end{tabular}

Table III

cuspation and coaptation of the condyle and disc during condylar translation.

This clicking can also occur because of friction between ligaments or as the condyle passes in front of the articular eminence of the temporal bone in a kind of subluxation from hyper-translation.

\section{3-2 - 2 - Crepitation}

Crepitation resembles the sound of wet sand moving over a surface. In dentistry, it is usually evoked by some change in the articular surfaces that disrupt their 'gliding' contact.

\section{3 - 3 - Pain}

Pain can be highly variable, occurring spontaneously or being triggered by mastication or palpation. Furthermore, it can be localized (e.g. to muscles or the TMJ) or referred to a distant region. 

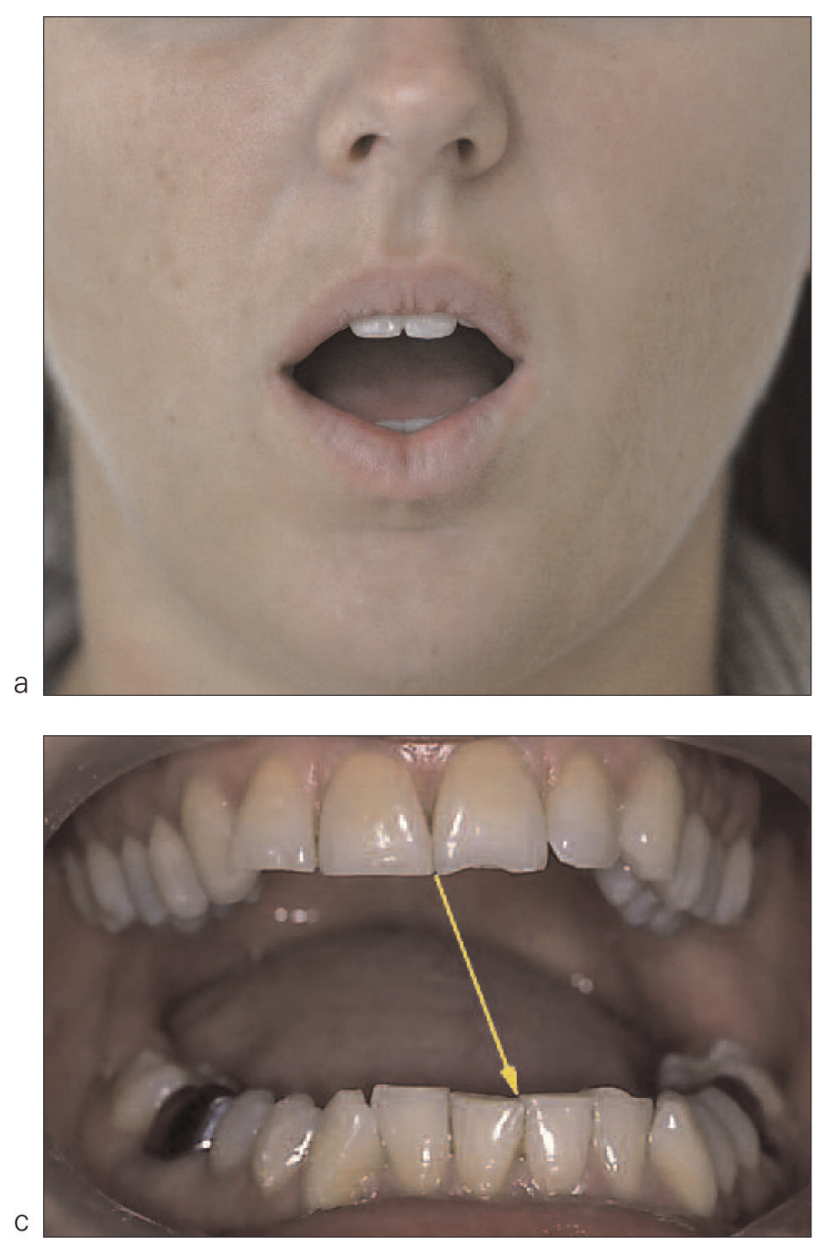

It is thus important for examiners to characterize precisely the nature of TMD pain according to its type, site, radiation, development, duration, context, any associated signs, and its impact on the patient's daily life.

In making a schematic representation of TMD pain, its extremes to be considered are:

- acute, experienced as penetration of a needle, preceding articular movement, exacerbated by mastication thus suggesting an articular malfunction, particularly if pain increases during passive testing

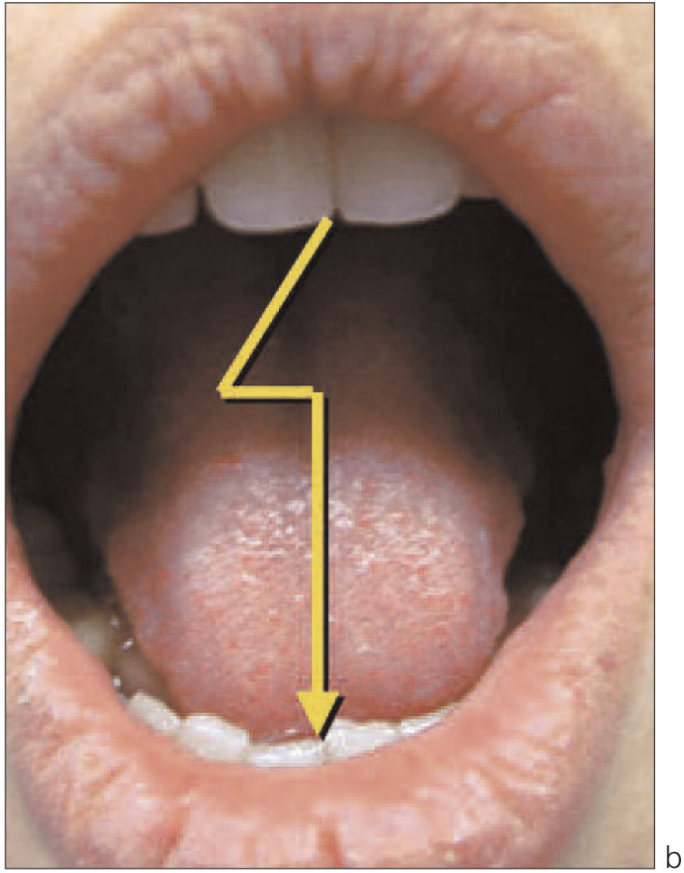

Figures 3a to 3c

Distinction between anomalies of mandibular movement.

a: Limitation of opening $(<30 \mathrm{~mm})$;

$b$ : Deviation in opening;

$c$ : Deflection in opening.

such as mobilization of the mandible placed under articular tension;

- dull pain evoking a feeling of heaviness during clenching, for example, that is more diffuse in the masseter muscle, near the ear and in the temporal bone, suggesting an origin in muscular malfunction.

Referred TMD pain is more complex and more difficult to analyze and diagnose precisely because of the distance between its probable site of origin and the location where it manifests. Orthodontists and general practitioners rarely see this type of slowly developing chronic somatic pain. 


\section{3 - 4 - Symptoms potentially associated with TMD}

A certain number of highly inconsistent, non-specific symptoms that cannot be considered as reliable elements for establishing a positive diagnosis of TMD include:

- otic complaints such as tinnitus, sensation of blockage, and sensations of exaggerated or diminished hearing;
- ocular disturbance such as peri or retro-orbital discomfort, and problems of accommodation;

- cephalic discomfort derived from tension of the frontal, temporal, and sub-occipital musculature;

- neurovegetative manifestations of edema, rhinorrhea, and excessive lacrimation.

\section{4 - IMPORTANCE OF DIFFERENTIAL DIAGNOSIS}

Taking into account the serious prognosis of other disorders, whose symptomology is similar to that of TMD, practitioners confronted with maladies of the masticatory system must focus on excluding other possibilities in making a differential diag-

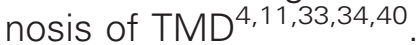

\section{5 - DIAGNOSTIC CLASSIFICATION}

The large number of diagnostic elements that examiners must take into consideration makes it essential for them to use a precise system of classification for malfunctions of the masticatory system that, for each type, associates an ensemble of clinical and paraclinical signs and symptoms together with therapeutic suggestions.

The development of a clearer nosology of malfunctions will, accordingly, contribute to a standardization of diagnosis of the two types of TMD (muscular and articular (Tables VI and
Such a diagnosis will be based both on pain and functional handicaps. Examiners must therefore have a clear understanding of the gamut of craniofacial pain and discomfort ${ }^{11,36,37}$ (Tab. IV) and articular disorders ${ }^{6}$ (Tab. V).

VII)) and their optimal therapy in the field.

\section{5 - 1 Muscular malfunctions}

Muscular malfunctions are the most frequent cause of anomalies of mandibular movement such as limitation of amplitude and dyskinesia.

\section{- Muscular type of pain (Fig. 4)}

The precise characterization of the pain experienced is an important component of an effective diagnosis of TMD. 


\section{Classification of craniofacial pain}

\begin{tabular}{|l|l|}
\hline \multicolumn{1}{|c|}{ Intracranial pain } & \multicolumn{1}{c|}{ Extracranial pain } \\
\hline $\begin{array}{l}\text { Structural (e.g. tumor, aneurism, abscess, } \\
\text { Hematoma, edema) }\end{array}$ & $\begin{array}{l}\text { Neuropathic, neurogenic } \\
\text { Paroxysmal : trigeminal, glossopharyngeal, upper laryngeal, } \\
\text { and occipital neuralgic } \\
\text { Continual : acute herpes, post-herpetic chronic neuralgic. }\end{array}$ \\
\hline $\begin{array}{l}\text { Primary cephalic, neurovascular pain: } \\
\text { migraine, vascular, chronic hemi-cranial } \\
\text { paroxysmal chronic tension headache }\end{array}$ & Eye, nose, throat (otitis, sinusitis) \\
\hline $\begin{array}{l}\text { Secondary headache (rebound, traumatic, } \\
\text { Hyperthermal, infectious, drug related) }\end{array}$ & Intraoral pain (dental, mucogingival, salivary gland, tongue) \\
\cline { 2 - 2 } & Musculoskeletal pain \\
\cline { 2 - 2 } & Cervical anomalies \\
\cline { 2 - 2 } & Masticatory malfunction \\
\hline
\end{tabular}

Table IV

\begin{tabular}{|l|l|}
\hline \multicolumn{2}{|c|}{ Differential diagnosis of non-TMD articular maladies } \\
\hline \multirow{2}{*}{ Infectious septic arthritis } & Acute, sub-acute, or chronic \\
\hline Inflammatory rheumatism & Rheumatoid arthritis \\
\cline { 2 - 2 } & Chronic juvenile arthritis \\
\cline { 2 - 2 } & Ankylosing spondylitis \\
\cline { 2 - 2 } & Psoriatic arthritis \\
\hline \multirow{2}{*}{ Degenerative lesions (Arthrosis) } & Reactive arthritis \\
\hline Synovial chondromatosis & Structural or mechanical arthrosis \\
\hline Villonodular synovitis & \\
\hline Condylar osteonecrosis & \\
\hline Metabolic arthropathy & \\
\hline Malformations & \\
\hline Condylar tumors and hyperplasia & \\
\hline
\end{tabular}

Table V

Myalgia, or muscle pain, may come from muscle bundles, tendons, or fascia. According to Bell ${ }^{3}$, muscle pain is the most frequent factor in head and neck discomfort. It is diffuse, described by patient as continual, deep, dull, and felt, especially, when teeth are clenched or under pressure. Its varying intensity, which is difficult for patients to localize and often appears beneath the malar and temporal muscles and more rarely mesial to the 


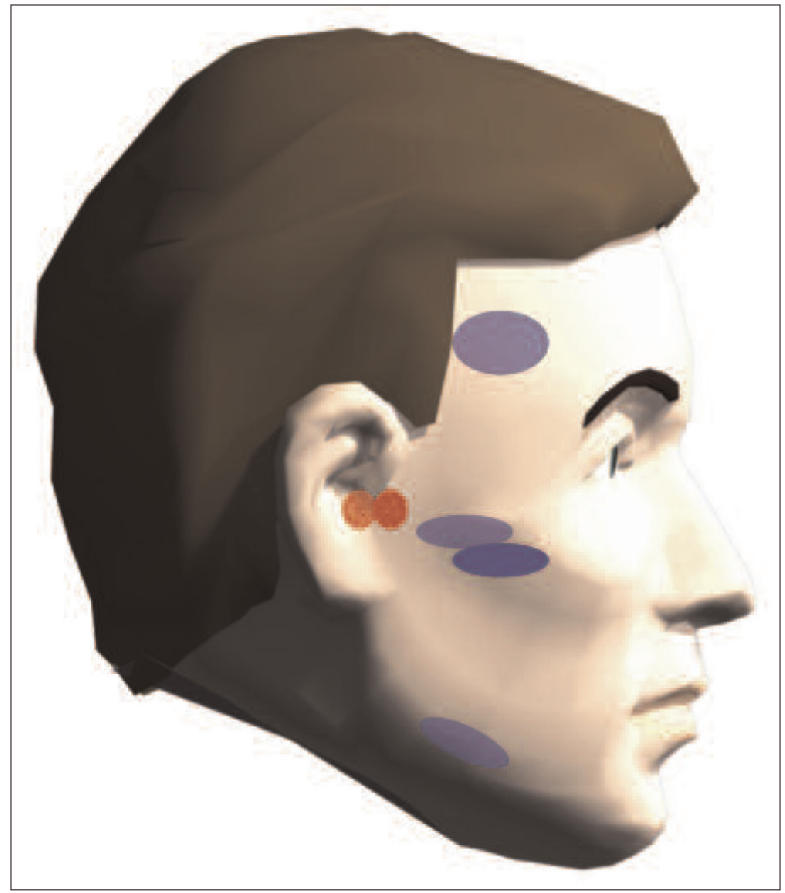

Figure 4

Schematic representation of the sites most frequently experiencing muscular (in blue) and articular (in red) pain.

Diagnostic classification of malfunction in the masticatory muscles

\begin{tabular}{|l|l|}
\hline Acute attacks & Splinting reflex \\
\hline & Muscular curvature \\
\hline & Spasm \\
\hline Chronic attacks & Myofacial pain (trigger points) \\
\hline & Myositis \\
\hline & Contraction (myostatic or fibrous) \\
\hline
\end{tabular}

Table VI

TMJ, sometimes causes errors in differential diagnosis between articular and muscular TMD.

The pain, associated with function, is exacerbated by palpation of muscles, and, in relation to its duration, can be considered acute or chronic.
Muscular pain is a deep somatic pain that can be accompanied by central secondary effects including autonomic and motor sensitivity, frequently resulting in restriction of mandibular movements related to muscular spasm. 
In this article, we propose a classification of muscular malfunctions based on that formulated by the American Academy of Orofacial Pain (Tab. VI).

\section{5 - 1 - 1 - Splint reflex}

Splinting is a protection reflex initiated by the central nervous system (CNS) provoking muscular contraction and pain intended to protect an injured region from further trauma. The CNS increases the activity of an antagonist muscle when its agonist contracts, as occurs when the masseters contract during jaw opening.

In itself, splinting is a physiological, not a pathological response of the neuromuscular system.

\section{- Etiology}

The splinting reflex is activated immediately after the occurrence of one of a number of etiological events, including :

- an alteration in proprioception or sensitivity after the sudden appearance of an occlusal high point perhaps caused iatrogenically by an orthodontic adjustment or placement of a prosthesis; a long period of mouth closure, caused, perhaps, by an extended dental procedure; clenching or bruxism, traumatic application of local anesthesia, or TMJ malfunction;

- continual deep pain within a muscle or associated structure, such as tendons, ligaments, or articulations of teeth;

- stress, which influences the action of the muscles of mastication through the intermediary of the gamma-efferent loop in muscle bundles and can, accordingly, provoke clenching and bruxism ${ }^{13,41}$.

\section{- Clinical signs}

- Muscular malfunction: pain limits the patient's ability to move their mandible; however, examiners can encourage patients to recover their normal amplitude of mandibular activity.

- Absence of pain when mandible is at rest.

- Aggravation of pain in function.

- Sensation of muscular weakness.

\section{- Treatment}

Because splinting, or immobilization, is a normal response of the central nervous system, the dental examiner should focus on determining the etiology of the TMD before eliminating that source of disturbance, after which the muscular retraction reflex should rapidly dissipate. If, in follow-up visits, the patient appears to have a major occlusal discrepancy related to recent tooth movements, dentists should deal either with that anomaly or by stabilizing the occlusion, encouraging remission with simple palliative remedies related to the etiology :

- giving advice on oral behavior with suggestions on how to rest the TMJ and the muscles;

- applying moist heat to painful muscles;

- using mild, short-term, peripheral analgesics;

- fabricating an acrylic occlusal splint designed for neuromuscular reconditioning and protection against nocturnal bruxism.

Typically, splinting reflexes can arise during any stage of orthodontic treatment in which tooth movement provokes a major occlusal anomaly such 


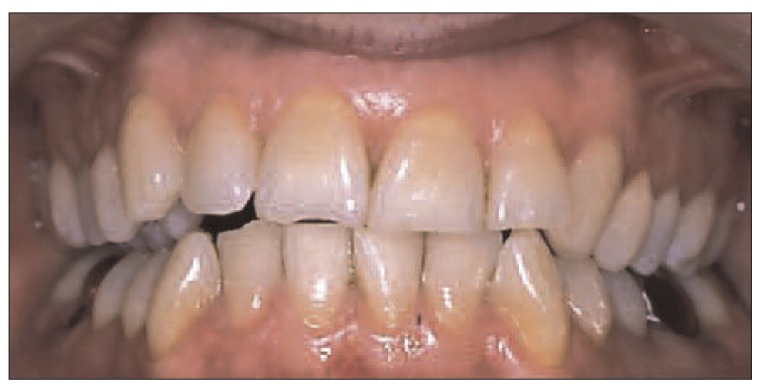

Figure 5

Intraoral view: a reflex splinting of the lateral pterygoid triggers a contralateral positioning of the mandible.

as as a transitory prematurity or an inadvertent, temporary occlusion of a tooth cusp with an attachment.

However, these reflexes may be totally independent of any orthodontic or other dental treatment. They may develop from, for example, a change in sleeping posture or from prolonged pressure on the right side of the chin provoking distal repositioning of the mandible and exertion of pressure on the left condyle triggering a splinting of the left lateral pterygoid muscle (Fig. 5).

\section{5 - 1 - 2 - Delayed Onset Muscle Soreness}

Delayed onset muscle soreness results from fatigue in the muscle fibers and is a primary, non-inflammatory reaction of muscular tissue to prolonged tension or to the splinting reflex. It is, accordingly, a change in the local muscular environment in which the central nervous system plays no part.

\section{- Etiology}

- Prolonged splinting reflex: a vicious circle can be created if the curved musculature can itself provoke a splinting reflex.

- Trauma: abusive use of muscle groups in gum chewing or, iatrogenically, from injection of a local anesthetic.

- Prolonged crispation of clenched teeth, a noxious occlusal habit.

\section{- Clinical signs}

- Muscular malfunction: a slight decrease in the amplitude of active mandibular movement. However, the examiner can gently guide the patient's jaw into movements of maximum amplitude.

- Slight pain when the jaw is at rest.

- Pain exacerbated by function.

- Muscular weakness.

- Affected muscle is painful on palpation.

Frequently examiners will note that muscular volume is greater with increased use of that particular muscle group.

\section{- Treatment}

- Eliminate the initial cause of the muscle splinting reflex responsible for the onset of this vicious circle.

- Reduce muscle tension by limiting the use of affected muscles in habit activity.

- Give patients behavioral counseling with regard to diet, the importance of resting muscles, education in muscle relaxation techniques, and increasing awareness of daily clenching episodes. The patient can, and should, continue to use affected muscles but not force them beyond the pain threshold.

- Advocacy of psychological relaxation techniques if necessary.

- Use of an acrylic occlusal splint designed for neuromuscular 
reconditioning and protection against nocturnal bruxism.

- Using mild, short-term, peripheral analgesics and muscle relaxants.

Clenching of teeth remains one of the principle causes of TMD, primarily affecting the masseter muscles where the site of pain may be so deep that examiners confuse it with pain originating in the TMJ.

In orthodontics, paradoxically, this type of muscle curvature frequently occurs after termination of treatment when the newly acquired correct intercuspation allows patients to clench their teeth in a way that was not possible when the malocclusion existed.

\section{5 - 1 - 3 - Muscular spasm}

A muscle spasm is a violent, acute, sudden and involuntary contraction of muscle tissue provoked by the central nervous system in which the fibers shorten and become painful. The contraction is continual and can be verified by surface electromyography (EMG) that shows considerable muscular activity at rest, in contrast to other types of muscle problems. A muscle spasm, with its very painful cramps, can last for a few minutes up to a few days. However, they rarely occur in the orofacial area.

\section{- Etiology}

The etiology of muscle spasms is not yet perfectly understood but several factors seem to be involved:

- local conditions such as muscular fatigue and electrolytic imbalance. Contraction seems to respond to exaggerated excitation of alpha motoneurons creating a pain-spasm cycle. The ischemia that follows these events solidifies the contraction leading to muscle fatigue with formation of lactic acid and the liberation of the peptide signaling mediator, bradykinin;

- variation among individuals' susceptibility to muscle spasms may derive from systemic factors that have not yet been elucidated.

\section{- Clinical signs}

- A marked limitation of mandibular movement caused by muscle spasms. Mouth opening, for example, will be limited when the masseters are affected.

- Acute occlusal malfunction, e.g. when the lower head of the inferior pterygoid is in spasm, contralateral anterior contacts and an ipsilateral dis-occlusion will occur during maximal inter-cuspation.

- Severe pain at rest and during function that may be acute and lancinating, radiating toward the ears, temples, and cheeks.

- Upon palpation, the muscle will be firm and the patient will likely experience pain.

\section{- Treatment}

It is important for the practitioner to initiate treatment of the muscle spasm promptly to prevent the development of myostatic or fibrous contraction (cf. infra).

- Kinesitherapy or physical therapy: the application of heat and massage is often effective at the beginning of treatment; later, after a few days, patients can begin stretching exercises to restore proper function.

- Short-term use of medication, including peripheral analgesics and muscle relaxants.

- If the contracting muscle resists attempts towards relaxation, 
practitioners may use local anesthesia to relieve the tension within it.

- Practitioners may begin to eliminate etiological factors, including occlusal prematurites and, possibly, overall stress.

- An acrylic splint may be indicated to promote neuromuscular reconditioning and control nocturnal bruxism and clenching that may be etiologic factors.

These muscular malfunctions of the masticatory system are among the most frequently encountered problems that orthodontists confront in their daily practices.

This disturbance is ubiquitous, and curvature accompanied by pain is also a revealing sign of some unwelcome occlusal parafunctions such as clenching. Therapeutic tooth movement must inevitably create transient "malocclusions" that trigger clenching reflexes, so orthodontists see this phenomenon more frequently than do their general practitioner colleagues.

Nevertheless, both groups of practitioners must know how to discern this discrepancy and how to institute a prompt therapeutic program to eliminate it.

There are, however, other clinical muscular malfunctions that represent chronic regional problems; here the peripheral symptoms, strongly influenced by the central nervous system and their chronic character of continuous pain present for more than 6 months, make local treatment highly uncertain. Management of these patients is best accomplished by multidisciplinary teams. However, even though such problems are beyond their level of specialization, orthodontists must understand them to make a satisfactory differential diagnosis (Tab. VI).

\section{5 - 2 - TMJ malfunctions}

Current understanding of the anatomical and physiological features of the TMJ strongly suggests that it functions best in a state of coaptation where the condyles and discs are supported by harmonious muscle function that persists in static positions of inter-cuspation as well as during dynamic action when mandibular movement dictates condylar displacements. In sagittal section, normal articulation is thought to involve the heads of the condyles contacting the intermediate zone of the temporomandibular discs and the two disc bands, with the whole ensemble resting on the posterior wall of the temporal eminence. This disc band is the terminal tendon of the lateral pterygoid muscle, which forms, along with the temporal, masseter, and medial pterygoid muscles, the tensor complex that covers the head of the condyle (Fig. 6a).

Examiners can verify the normality of the TMJ clinically or by means of a condylograph if they find the heads of the condyles are capable of ample, regular, and symmetrical translations, without any deviations, that are superposable during different types of mandibular movement. Working symmetrically, the two heads of the condyle allow the mandible to drop sufficiently in opening, between 40 and $50 \mathrm{~mm}$ in adults, without deviating to the right or left (Fig. $6 \mathrm{~b}$ and $6 \mathrm{c}$ ). 


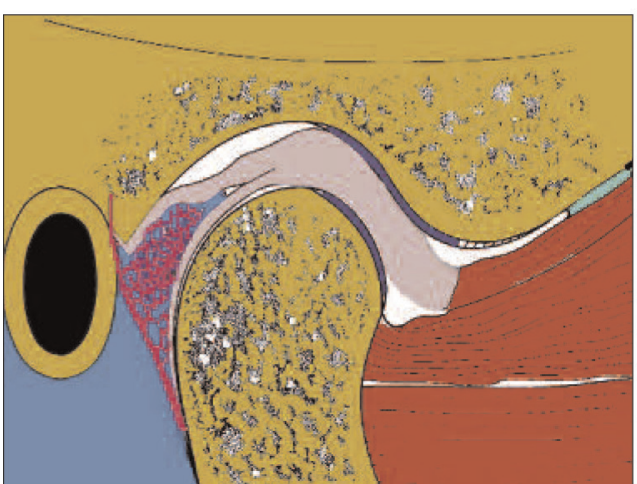

a

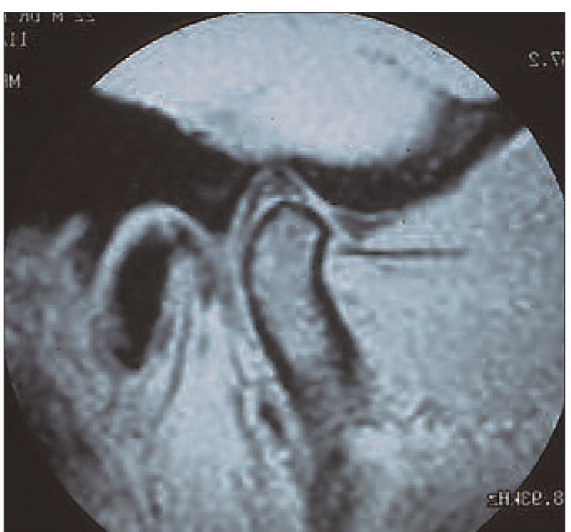

b

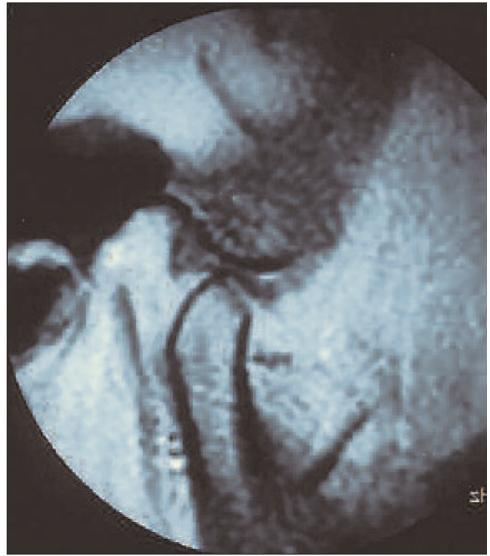

C

Figures $6 a$ to $6 c$

Models of the normal arrangement of TMJ components.

a: Schematic representation,

b: MRI view of normal TMJ, mouth closed: condyle, disc, temporal bone in coaptation;

c: MRI of normal TMJ, mouth open: condyle in translation.

\section{5-2 - 1 - Anomalies of the disc-condyle complex}

These disorders are disturbances of the relative position of the two components of the TMJ.

Functional, anatomic, or traumatic factors can cause varying degrees of disc displacement.

Situations differing from the normal anatomic relationships shown above have been described as disc displacement when, in most cases of separation it is, in fact, the head of the condyle that has moved distally, away from a disc that has remained, more or less, in place.

This displacement can be :

- partial or total in maximal intercuspation with a reduction in condylar translation (reducible disc displacement) or;

- total with no reduction during different movements of the mandible (permanent disc displacement).

\section{$>$ Reducible disc displacement} (Fig. 7).

Anatomically, in these cases the head of the condyle is no longer located in the intermediate zone of the disc, but rests on the posterior osseous ring, or glenoid. The displaced disc is usually in an anteromedial position, but sometimes lies in a directly anterior or anterolateral position $^{34}$.

\section{- Etiology}

- Condyles moving distally because of excessive looseness or overwork of some TMJ components caused by noxious habits or occlusal interferences.

- Hyperactivity of the tensor muscles of the disc, deep masseter, superior head of the lateral pterygoid, and posterior temporalis.

\section{- Clinical signs}

The pain suffered at the beginning of a TMD episode diminishes as the disorder becomes chronic and tissues 


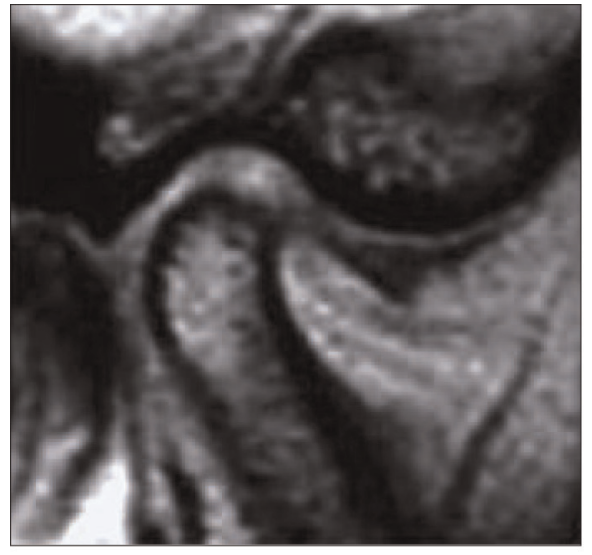

a

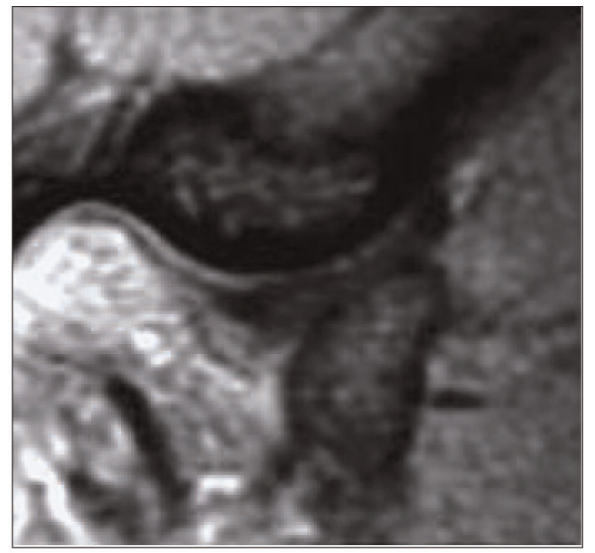

b
Figures $7 a$ and $7 b$

MRI of TMJ with non-permanent disc displacement. a: Mouth closed, condyle separated from disc;

b: Mouth closed: condyle and disc have re-connected. adapt to it. The inflammation of the bilaminar disc zone that accompanies the disc displacement, or distalization of the condyle decreases but clicking sounds become more noticeable and sharper as the condyles confront the osseous ring, or posterior glenoid of the disc.

In the excursive movements of opening, forward thrusting, or of contralateral movement right or left, clicking sounds of varying intensity correspond to condylar projection or re-coaptation of the condyle and disc, accompanied by an abrupt change of direction of the mandible in motion.
Examiners can palpate this lateral projection of the condyle.

They can also perceive a "reciprocal" clicking during excursive movements when the mandible is near, but not yet in, a position of maximum inter-cuspation.

Deviation in opening, in a bayonetlike projection is an important sign of disc displacement, but if the extent of opening is not restricted, the disorder is not permanent (Fig. 8).

\section{- Therapy}

Dentists treating TMD should not aim at re-capturing the displaced disc,

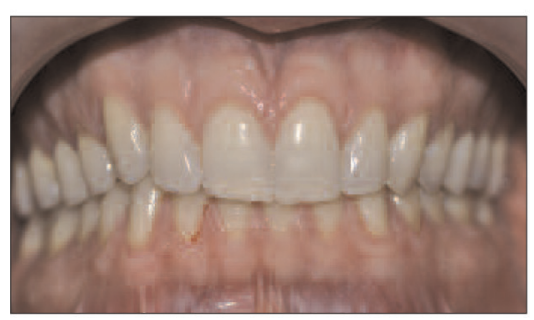

a

Figures 8 a to $8 \mathrm{c}$

Intraoral views of a patient with bayonet mandibular deviation with no reduction in opening amplitude, characteristic of non-permanent disc displacement. 


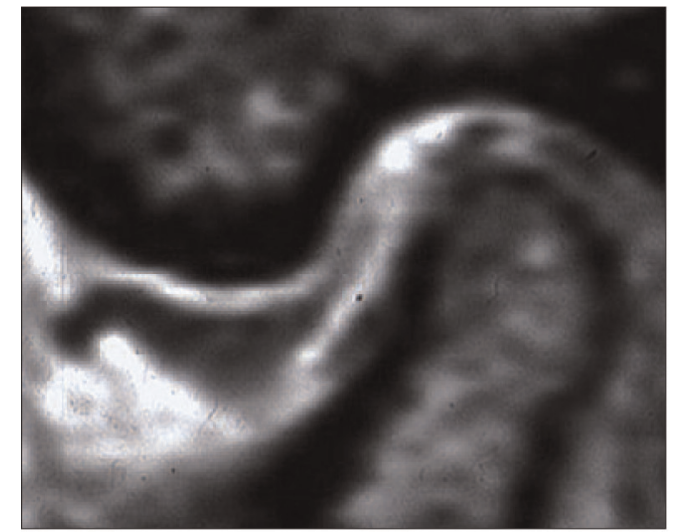

a

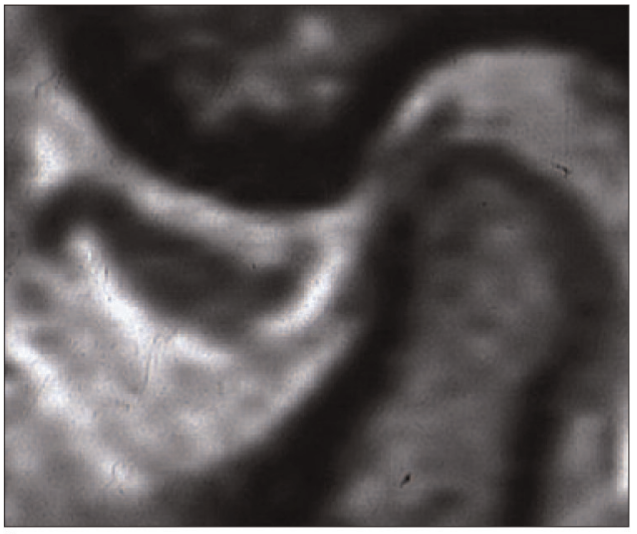

b
Figures $9 a$ and $9 b$

MRI of a TMJ with acute permanent disc displacement.

a: Mouth closed: disc displaced;

b: Mouth open: persistence of displacement and limited condylar translation.

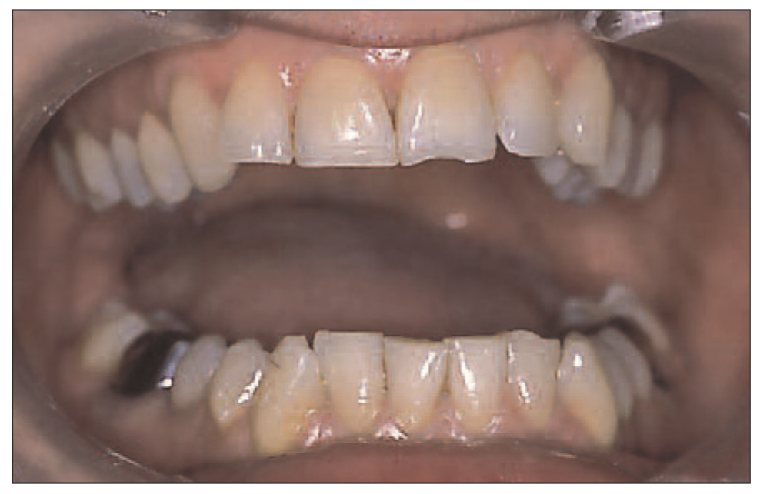

Figure 10

Deviation and decrease in opening amplitude are characteristic of permanent disc displacement.

which is a transient disorder, but at alleviating painful symptoms and optimizing condylar positions by encouraging the formation of fibrous tissue from the healing process between the condyle and the mandibular fossa, in the neo-disc area.

It is essential that treatment should be conservative, consisting of:

- advice on proper oral behavior;

- use of medication, peripheral analgesics or anti-inflammatory drugs;
- use of an occlusal neuromuscular reconditioning or decompression splint;

- kinesitherapy or physical therapy to reverse over-relaxation of TMJ tissues;

- optimization of occlusal functioning.

\section{> Permanent disc displacement}

Permanent disc displacement can be acute or chronic. In both cases, in maximum intercuspation, the head of the condyle lies behind the glenoid, or 

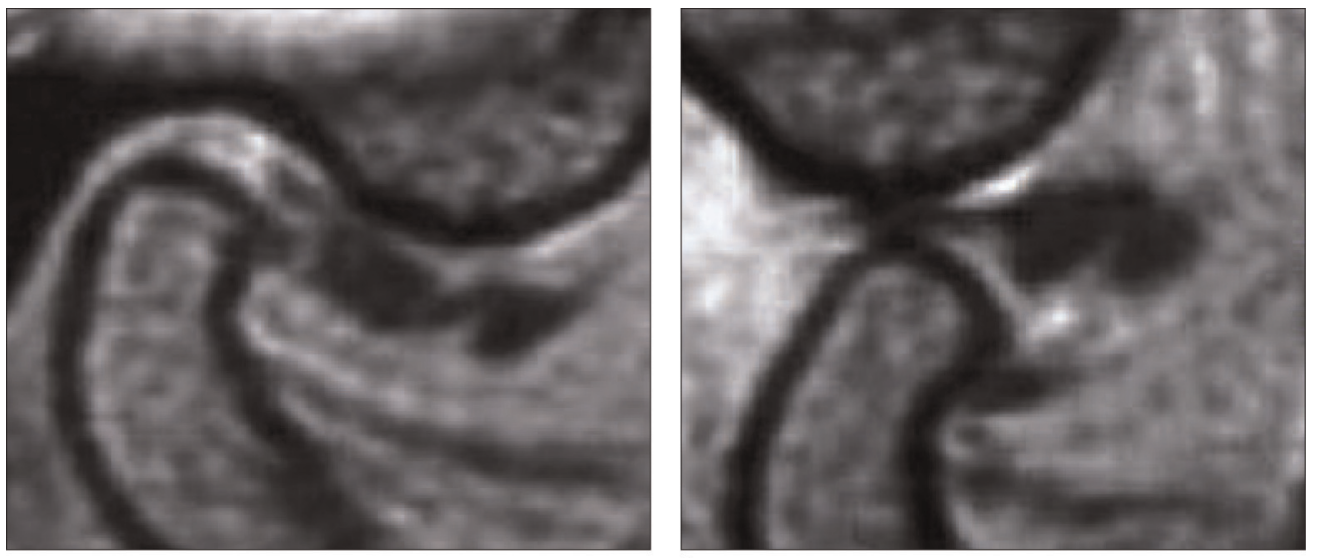

Figures 11a and $11 b$ MRI of a TMJ with chronic permanent disc displacement.

a: Mouth closed, disc displacement;

b: Mouth open: persistence of disc displacement, but normal condyle translation.

a

b

Diagnostic classification of articular malfunction in the masticatory system

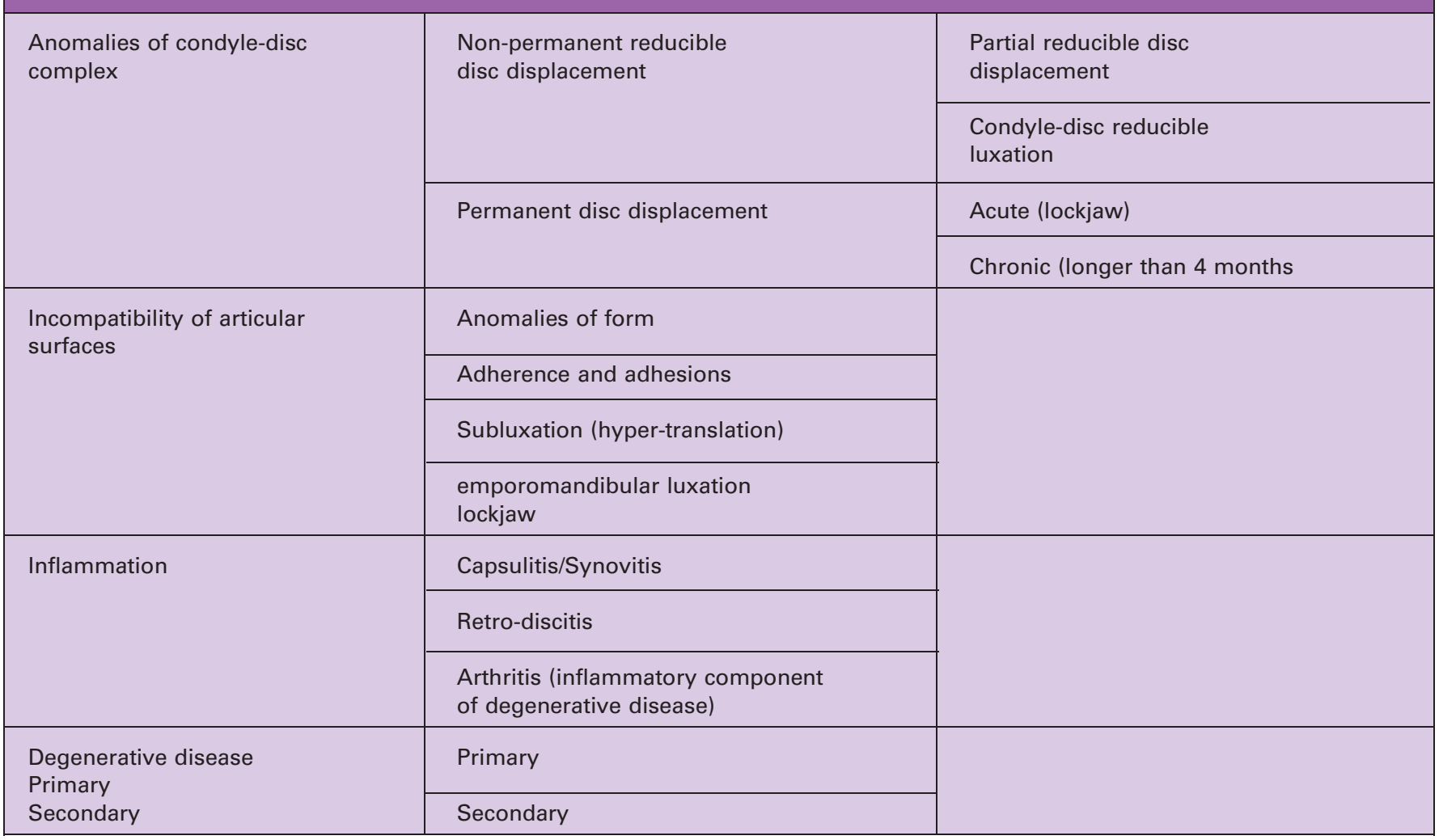

Table VII

osseous ring and remains in this position during translation movements without ever returning to condyle-disc coaptation.
Two versions of this situation can be described depending on whether the disc displacement is recent (in an 
acute phase) or is of at least 3-4 months duration (i.e. is chronic).

$>$ Acute permanent disc displacement (Fig. 9)

\section{- Etiology}

Acute permanent disc displacement frequently develops from an exacerbation of an earlier episode of reducible disc displacement that was first revealed in the intake interview when the patient reported a history of painless joint noises. However, they can abruptly turn into permanent displacement after trauma, dental treatment under general anesthesia, a whiplash injury, or sudden TMJ strain.

\section{- Clinical signs}

- Moderate-to-intense pain localized in the TMJ area that worsens on mouth opening.

- Considerable limitation of mouth opening, with deviation toward the affected side that sometimes provokes locked jaw syndrome and blocks excursion to the contralateral side (Fig. 10).

- Absence of joint noise.

- Treatment

- Medication with level II peripheral or central analgesics and anti-inflammatory drugs.

- If the permanent disc displacement is relatively recent, of a few hours or days duration, dentists may attempt to recapture the disc by using the Farrar maneuver and, with success, treat the problem like any other reducible displacement.

- If the permanent displacement is longer in duration, the therapeutic objective is conservative and consists of orthopedic management with a decompression splint of a healing space in the TMJ. The goal is amelioration of the tropic poten- tial of the space around the disc and the relaxation of attached ligaments to improve condyle translation.

The modalities of treatment are identical to those used for chronic permanent disc displacement (cf. infra).

\section{$>$ Chronic permanent disc displace- ment (Fig. 11) \\ - Etiology}

These always follow an episode of acute displacement that may have been asymptomatic. The etiology of chronic disc displacement is identical to that of acute displacement.

\section{- Clinical signs}

- Slight pain that diminishes at this evolving stage as the retro-disc tissues adapt to the TMD.

- Mandibular movements return to normal patterns as a result of compensatory hyper-rotation of the lower level of the TMJ or stretching of ligaments.

There is, accordingly, a considerable reduction of symptoms to a point where they are not clinically detectable. Twenty per cent of asymptomatic subjects are in this category ${ }^{29}$.

\section{- Therapy}

The conservative therapeutic objective is to encourage healing of the articular space orthopedically and to improve the relationship between the joint components, i.e to bring the disc closer to the condyle using:

- oral behavior counseling;

- decompression splint;

- periodic follow-up re-evaluations;

- and exercising extreme prudence when extensive orthodontic or prosthetic dental occlusal procedures are contemplated, because the disc displacement makes joint 


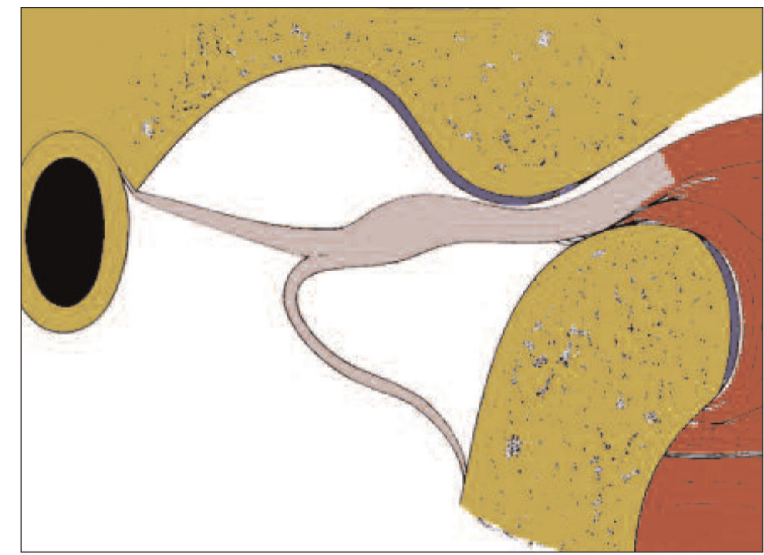

a

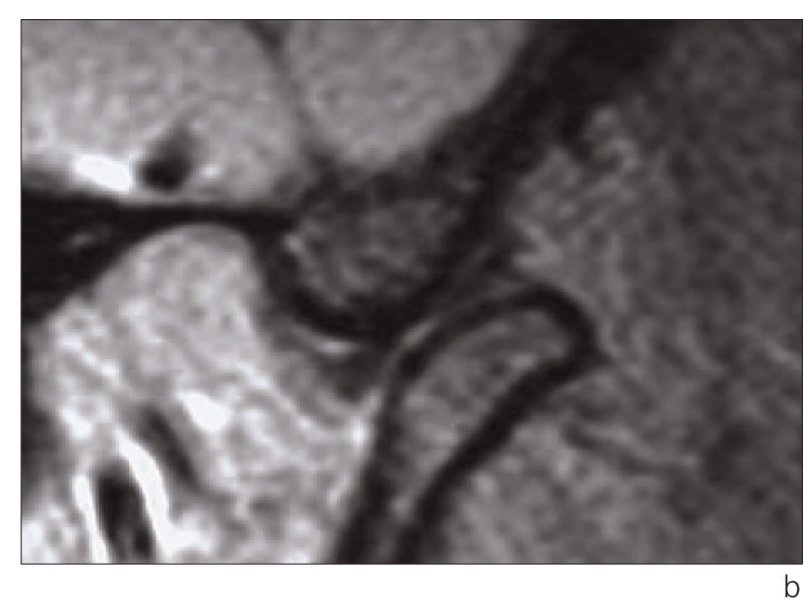

Figures $12 a$ and $12 b$

Differential diagnosis of reducible disc displacement and substantial subluxation. The 'clicking' of subluxation occurs at the point of maximal opening, which can be greater than $40 \mathrm{~mm}$, and is followed by hyper-rotation of the mandible.

relationships unfavorable as the patient's adaptive capacity is decreased.

At this point, the articular relationships are pathological but can be stabilized with treatment.

In Table VII, we have noted another group of disorders concomitant to this list of condyle-disc complex anomalies.

By carrying out a complete and accurate anamnesis and carefully analyzing clinical signs, examiners can usually construct a precise diagnosis.

\section{5-2 - 2 - Incompatibility of articular surfaces}

There are four ways in which articular surfaces may be incompatible: different shapes; adherences and adhesions; subluxation; and true temporomandibular luxation.

\section{$>$ Anomalies of the shape of articu- lar surfaces}

Included in this category are problems caused by morphological changes of the articular surfaces of the TMJ or of its disc.

For the articular surfaces, minitraumas (derived from habits or TMJ overloading) and major trauma are the etiological causes. These are responsible for articular sounds during mandibular excursive movements that may or may not be painful or deviated.

For the discs, the anomalies consist primarily of a thickening of the posterior osseous ring, a mucoid degeneration in adolescents, and disc calcification (chondrocalcinosis).

Clinical signs are quite different :

- occasional audible clicking sounds related to obstacles in the path of condylar translation ; 
- aberrant or variable condylar movements.

\section{$>$ Adherence and adhesion}

In adherence, articular surfaces are temporarily attached by synovial membranes, usually because of increased articular pressure caused by the microtrauma of clenching and bruxism. The principal clinical sign is difficulty in opening the mouth in the morning, which is usually accompanied by a clicking sound (as the synovium detaches) and then a return to normal mandibular movements.

Therapy consists of suppression of the etiological factors and the use of an occlusal splint as a protective device during sleeping hours.

Adhesions are the formation of irreversible intra-articular fibrous connections between condyles and discs or between the temporal bone and discs. These often evolve from adherences or follow an intra-articular hemorrhage caused by trauma or a surgical procedure.

Patients with these problems have abbreviated amplitude of one or more types of mandibular movement, depending on the site of the adhesion, accompanied by articular noises.

Patients are advised to avoid putting stress on the TMJ, and given gentle kinesitherapy or physical therapy to assist the condyles in making translational movements, arthroscopic lavage and debridement of the TMJ using the most advanced techniques.

\section{$>$ Subluxation (hyper-translation)}

(Fig. 12)

In cases of substantial acquired or systemic ligamentous laxity ${ }^{17}$ or of special morphological discrepancies of the temporal eminence, such as a short and inclined posterior surface or a long anterior surface, the translation of the condyles is no longer contained and the condyle head may pass entirely over the articular tubercle of the temporal bone, resulting in a temporomandibular luxation. This may be unilateral or bilateral.

When patients can reduce the condition themselves, it is described as a subluxation.

When patients with TMJs that are susceptible to subluxation open their jaws to the widest extent, a deep dull noise is heard, which can be confused with a sign of disc displacement. An identical sound accompanies mouth closure. The amplitude of mouth opening is exaggerated with a jump at the maximum point and with a nonrectangular closure.

Therapy is palliative, based on oral behavioral counseling on the dangers of yawning or eating large morsels of food, and on reinforcement exercises for the elevator muscles, the objective of which is to limit condylar translation.

\section{$>$ True temporomandibular luxa- tion (mouth-open lockjaw)}

When a locked open jaw does not reduce itself spontaneously this means the condyle has slipped beyond the articular eminence of the temporal bone and the lateral pterygoid and the masseter muscles have gone into spasm, preventing the patient from closing their mouth. This locked open mouth with moderate to very intense pain is a clear diagnostic sign. Usually a practitioner using the Nelaton maneuver can assist the condyle in re-integrating itself in the mandibular fossa ${ }^{24}$. 


\section{5 - 2 - 3 - Inflammation}

Inflammation of the TMJ itself can result from :

- anomalies of the condyle-disc complex ;

- micro- or macro-trauma ;

- and, rarely, from an infection.

The inflammation may affect the capsule (capsulitis), the synovial membrane (synovitis), the bi-laminar zone responsible for the vascularization and the innervation of the TMJ (retrodiscitis), or osseous tissues (arthritis).

\section{$>$ Capsulitis and synovitis}

Inflammation of the capsule or the synovial membrane (it is impossible to distinguish clinically between the two) derives from a series of microtraumatic incidents, or to a single major traumatic episode, and suppresses the functioning of the joint.

\section{- Clinical signs}

- Pain in extreme mandibular movements, opening and maximum contralateral excursion.

- Absence of pain in maximal intercuspation or in mastication.

- Pain on lateral palpation.

- Treatment

- Oral behavior counseling, and advocacy of periods of TMJ rest.

- Prescription of short-term non-steroidal or corticosteroid medication.

\section{$>$ Retro-discitis}

This inflammation of the retro-disc tissue is related to suppression of TMJ activity and the functional or traumatic distal position of the head of the condyle.

\section{- Clinical signs}

- Pain during maximal inter-cuspation occlusion or in mastication.

- Pain on palpation of retro-condylar region, through external auditory canal.

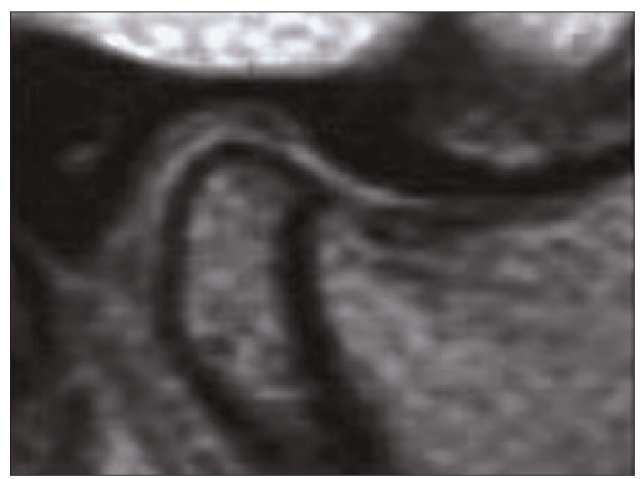

Figure 13

MRI of a TMJ with condylar arthrosis, showing an anterior osteophytic beak.

\section{- Treatment}

- Oral behavior counseling.

- Prescription of short-term non-steroidal or corticosteroid medication.

- Use of a splint for several to place the mandible in a slightly more anterior position.

\section{$>$ Arthritis}

This is an inflammatory component of a degenerative disease affecting the TMJ (cf. infra).

\section{- Clinical signs}

- Pain localized in the TMJ during mandibular movements.

- Treatment

- Oral behavior counseling.

- Prescription of short-term non-steroidal or corticosteroid medication.

- Use of a decompression orthesis.

\section{5 - 2 - 4 - Degenerative TMD (arthrosis) (Fig. 13)}

In this destructive process, the articular surface of the condyle and/ or the articular tubercle of the temporal bone are altered due to over-loading or macro-/micro-trauma to both right and left TMJ. 
The equilibrium between the synthesis and degradation of extracellular matrix components controlled by chondrocytes is disturbed, provoking a cartilaginous deterioration that is expressed biologically by:

- swelling and softening of cartilage (chondromalacia);

- the localized deterioration of collagenous fibrils at the interior of the matrix (fibrillation) and an associated inflammatory response through the liberation of proteolytic enzymes;
- the loss of cartilaginous integrity with puffiness, horizontal fissures, shrinking, and adherences;

- the complete destruction of some cartilage exposing sub-chondral osseous tissue;

- the formation, by remodeling, of sclerotic osseous tissue.

TMJ degenerative disease, accordingly, represents a disturbance of the balance between degenerative and regenerative processes of cartilage, bone, and synovial fluid, all accompanied by secondary inflammatory phenomena (cf. supra).

\section{6 - DEALING WITH TMD IN THE CLINICAL SETTING}

Before beginning any treatment, orthodontists should establish whether a prospective patient had previously suffered from TMD or presents any risk factors for its future development.

For obvious medicolegal reasons, it is essential that they make a permanent record of any articular sounds, anomalies of mandibular movement or accompanying pain. It is also imperative that formal informed consent for the treatment of any specific clinical situation is obtained before strarting therapy, and, according to Michelotti ${ }^{32}$, updated every six months during the course of treatment.

If signs or symptoms of TMD are present, especially painful ones, the clinician must establish a differential diagnosis by first excluding any pathological entities that are not TMD in nature.

The differential diagnosis having been completed, the orthodontist must now establish a positive, rea- soned diagnosis, based on the classification system we have discussed in detail.

Management of TMD problems should emphasize conservative, reversible techniques including modest medication, counseling, exercises, physical therapy, kinesitherapy ${ }^{31}$ and occlusal splints ${ }^{25}$. Michelotti ${ }^{32}$ suggests that orthodontists adopt the invariable principle of not undertaking orthodontic treatment for patients that are already in pain. For patients with a history of TMD, with or without pain, the disturbances that exist in their musculoskeletal system make it highly susceptible to complications during any type of occlusal rehabilitation ${ }^{\text {9-36 }}$.

After patients have entered a period of remission from painful symptoms, orthodontists can consider undertaking orthodontic treatment, but must always be mindful of their special needs and risks that include TMJ instability, history of TMD, and a propensity for tooth clenching. 
If, during the course of orthodontic treatment, patients develop signs of TMD, practitioners should treat these as they would a patient not undergoing orthodontic treatment by :

- providing all useful information about the nature of TMD, including the fluctuation of its symptoms and the bewildering variety of forms it may take. Relying on the advice of an occlusion specialist, practitioners can usually reduce the enormity of the episode and reinforce the explanations provided previously to reassure the patient. It should also be possible to acquire the data needed to make a precise diagnosis and formulate a treatment plan that will probably include the postponement of active orthodontic treatment to avoid introdu-

\section{7 - CONCLUSION}

Orthodontists may be confronted by a TMD problem at any time and must be prepared at least to describe it completely if not to make a full diagnosis.

This responsibility becomes absolute when orthodontists undertake global rehabilitation projects that require a valid mandibular reference position, centric relation, which is dependent upon the state of the musculoarticular relationship.

By accurately uncovering the origins of an existing malfunction and asses- cing possible exacerbating factors. A multi-faceted management plan (cf. supra) may then be instigated.

At the conclusion of orthodontic treatment, the orthodontist should present TMD patients with an unambiguous analysis of the specific risk factors that apply to them, together with behavioral advice and management techniques specific to that patient with the aim of optimizing function and minimizing any TMD relapse.

After therapy, orthodontists should intervene promptly to manage any recurrence of TMD signs or symptoms, again establishing a precise diagnosis and managing the TMD problem no differently than for a "non-orthodontic" patient.

sing the risk factors at play, orthodontists can adopt an appropriate management stance and modulate the orthodontic treatment plan to serve the patient's best interests. Orthodontists must remain vigilant, fully aware of the occlusal situation and ready to adjust occlusion whenever needed without forgetting the need to establish a differential diagnosis that rules out "non-TMD" disorders that have the potential to be far more deleterious. 


\section{REFERENCES}

1. Ash MM. Paradigmatic shifts in occlusion and temporomandibular disorders. J Oral Rehabil 2001; 28:1-13.

2. Ash MM. Occlusion: Réflexions on science and clinical reality. J Prosthet Dent 2003;90:373-84.

3. Bell WE. Orofacial Pains: Classification, Diagnosis, Management. $4^{\text {th }}$ ed. Chicago: Year Book, 1989: 239-84.

4. Cairns B, List T, Michelotti A, Ohrbach R, Svensson P. JOR-CORE recommendations on rehabilitation of temporomandibular disorders. J Oral Rehabil 2010;37:481-9.

5. Carlsson GE. Epidemiology and treatment need for temporomandibular disorders. J Orofac Pain 1999;13:23-27.

6. Chassagne JF, Chassagne S, Deblock L, Gillet P, Kahn JP, Bussienne JE, Pierucci F, Fyad JP, Simon E. Pathologie non traumatique de I'articulation temporomandibulaire. Encycl Méd Chir, Stomatologie, 22-056-R-10, Odontologie, 23-446-D-10, 2003.

7. Clark GT, Tsukiyama Y, Baba K, Watanabe T. Sixty-eight years of experimental occlusal interference studies: what have we learned? J Prosthet Dent 1999;82:704-13.

8. Chiappe G, Fantoni F, Landi N, Biondi K, Bosco M. Clinical value of 12 occlusal features for the prediction of disc displacement with reduction (RDC/TMD Axis I group Ila). J Oral Rehabil 2009;36: 322-29.

9. DeBoever J, Carlsson GE, Klineberg IJ. Need for occlusal therapy and prosthodontic treatment in the management of temporomandibular disorders. Part I. Occlusal interferences and occlusal adjustment. J Oral Rehabil 2000;27:367-79.

10. De Leeuw R, Boering G, Stegenga B, de Bont LG. Symptoms of temporomandibular joint osteoarthrosis and internal derangement 30 years after non-surgical treatment. Cranio 1995;13:81-8.

11. De Leeuw R (ed). Orofacial pain: guidelines for assessment, diagnosis, and management. $4^{\text {th }}$ ed. Chicago: Quintessence Pub., 2008:129-204.

12. Forssell $H$, Kalso E, Koskela P, Vehmanen R, Puukka P, Alanen P. Occlusal treatments in temporomandibular disorders: a qualitative systematic review of randomised controlled trials. Pain 1999;83:549-60.

13. Gameiro GH, Da Silva Andrade A, Nouer DF, Ferraz de Arruda Veiga MC. How may stressful experiences contribute to the development of temporomandibular disorders? Clin Oral Investig 2006;10:261-8.

14. Giraudeau A, Orthlieb JD, Laplanche O, Mantout B, Cheynet F, Chossegros C, Sarrat P. Dérangements intracapsulaires de l'articulation temporo-mandibulaire, proposition de classification. Cah Prothèse 2001;114:51-9.

15. Gola R, Chossegros C, Orthlieb JD. Syndrome algodysfonctionnel de I'appareil manducateur. Paris: Masson, 1992.

16. Guyot L, Thiery G, Brignol L, Chossegros C. Abord conservateur des dysfonctions de I'appareil manducateur. EMC (Elsevier Masson SAS, Paris), Odontologie/Orthopédie dentofaciale, 23-499-A-12, 2007.

17. Huang GJ, Rue TC. Third-molar extraction as a risk factor for temporomandibular disorder. J Am Dent Assoc 2006;137(11):1547-54.

18. John MT, Dworkin SF, Mancl LA. Reliability of clinical temporomandibular disorder diagnoses. Pain 2005;118(1-2):61-9.

19. Kirveskari P, Alanen P. Scientific evidence of occlusion and craniomandibular disorders. J Orofac Pain 1993;7: 235-40.

20. Kirveskari P, Jämsä T, Alanen P. Occlusal adjustment and the incidence of demand for temporomandibular disorder treatment. J Prosthet Dent 1998;79:433-8.

21. Laplanche O, Pédeutour P, Duminil G, Bolla M, Mahler P. Dysfonctionnements de I'appareil manducateur. Paris : Encycl Med Chir, Odontologie, 23-435-E-20, 2001.

22. Laplanche $O$, Pedeutour $P$, Orthlieb JD. Que faire face à un bruit articulaire ? Information Dentaire 2002;84(5):259-63. 
23. Laplanche O, Pédeutour P, Duminil G, Mahler P. Dépistage des anomalies de I'occlusion. Réalités Cliniques 2004;15(2):141-56.

24. Laplanche O, Pédeutour P, Duminil G, Hermann E. L'urgence des dysfonctionnements de I'appareil manducateur. Rev Orthop Dento Faciale 2011;45:159-174.

25. List T, Axelsson S. Management of TMD: evidence from systematic reviews and metaanalyses. J Oral Rehabi 2010;37:430-51.

26. Luther F, Layton S, McDonald F. Orthodontics for treating temporomandibular joint (TMJ) disorders. Cochrane Database Sys Rev 2010;7(7):CD006541.

27. McNamara JA Jr. Orthodontic treatment and temporomandibular disorders. Oral Surg Oral Med Oral Pathol Oral Radiol Endod 1997;83(1):107-17.

28. Manfredini D, Bucci MB, Montagna F, GuardaNardini L. Temporomandibular disorders assessment: medicolegal considerations in the evidencebased era. J Oral Rehabil 2011;38:101-19.

29. MarguellesBonnet RE, Carpentier P, Yung JP, Defrennes D, Pharaboz C. Clinical diagnosis compared with findings of magnetic resonance imaging in 242 patients with internal derangement of the TMJ. J Orofac Pain 1995;9:244-53.

30. McNeill C. Temporomandibular Disorders: guidelines for classification, assessment and management. Chicago: Quintessence Pub., 1996.

31. Michelotti A, de Wijer A, Steenks M, Farella M. Homeexercice regimes for the management of nonspecific temporomandibular disorders. J Oral Rehabil 2005;32:77985.

32. Michelotti A, lodice G. The role of orthodontics in temporomandibular disorders. J Oral Rehabil 2010;37:411-29.

33. National Institutes of Health Technology Assessment Conference on management of temporomandibular disorders. Bethesda, Maryland, April 29-May 1, 1996. Proceedings. Oral Surg Oral Med Oral Pathol Oral Radiol Endod. 1997;83:49-183.

34. Okeson J.P. Management of temporomandibular disorders and occlusion. $4^{\text {th }}$ ed. St Louis: Mosby, 1998.

35. Orthlieb JD. Gnathologie fonctionnelle. Vol. 1 : Occlusion et restauration prothétique. Paris : CdP, 2009.

36. Orthlieb JD, Chossegros C, Cheynet F, Giraudeau G, Mantout B. Cadre diagnostique des dysfonctionnements de l'appareil manducateur. Inf Dent 2004;19:1196-203.

37. Orthlieb JD, Schitly J, Maniere Ezvan A, Brocard D. Occlusodontie pratique. Paris : CDP, 2000:3-11.

38. Philippe J. L'orthodontie de I'adulte. La bibliothèque orthodontique. Paris : SID, 1989.

39. Pullinger AG, Seligman DA, Solberg WK. Temporomandibular disorders. Part II: Occlusal factors associated with temporomandibular joint tenderness and dysfunction. J Prosthet Dent 1988;59:363-7.

40. Rozencweig D. Algies et dysfonctions de l'appareil manducateur. Paris : CDP, 1994.

41. Sato S. Slavicek R. The masticatory organ and stress management. J Stomat Occ Med 2008;1:51-7.

42. Sarlani E, Greenspan JD. Why look in the brain for answers to temporomandibular disorder pain? Cells Tissues Organs 2005;180:69-75.

43. Tsukiyama Y, Baba K, Clark GT. An evidence-based assessment of occlusal adjustment as a treatment for temporomandibular disorders. J Prosthet Dent 2001;86:57-66. 